\title{
Pulmonary rehabilitation improves functional capacity in patients 80 years of age or older
}

\author{
Marcel A Baltzan MD FRCPC, Hany Kamel MD, Arlene Alter PT, Michael Rotaple MD FRCPC, \\ Norman Wolkove MD FRCPC FCCP
}

\begin{abstract}
MA Baltzan, H Kamel, A Alter, M Rotaple, N Wolkove. Pulmonary rehabilitation improves functional capacity in patients 80 years of age or older. Can Respir J 2004;11(6):407-413.
\end{abstract}

OBJECTIVES: There is limited evidence that pulmonary rehabilitation improves exercise capacity in older patients with chronic respiratory disease. The objective of the present study was to determine whether patients 80 years of age or older gain similar benefits from pulmonary rehabilitation as do younger patients.

DESIGN: Outcomes were compared in 230 consecutive inpatients with moderate to severe lung disease who participated in a comprehensive pulmonary rehabilitation program during a one-year period. Outcomes included 6 min walk test distance (6MWT), the number of stairs completed in 2 min (2MST), Borg dyspnea scores after exertion and objective functional scores.

RESULTS: There were no differences between older ( 80 to 91 years, $\mathrm{n}=43)$ and younger patients $(\mathrm{n}=187)$ with respect to sex, forced expiratory volume in $1 \mathrm{~s}$ (mean $0.77 \mathrm{~L}$ versus $0.72 \mathrm{~L}$ ) or number of chronic medical diagnoses (2.4 versus 2.7 ). Older patients were less frequently survivors of mechanical ventilation $(2.3 \%$ versus $16 \%)$. Baseline 6MWT (133 m versus $144 \mathrm{~m} ; \mathrm{P}=0.48$ ) and 2MST (5.2 laps versus 6.5 laps; $\mathrm{P}=0.067$ ) were similar but global function was lower ( 85 versus $89 ; \mathrm{P}=0.040)$ in older patients than in younger patients, respectively. After pulmonary rehabilitation, all outcomes improved significantly regardless of age (all before-after comparisons $\mathrm{P}<0.0001)$. Younger patients improved with a higher discharge 6MWT (231 m versus $185 \mathrm{~m} ; \mathrm{P}=0.004)$ and similar discharge 2MST (9.3 laps versus 7.9 laps; $\mathrm{P}=0.070$ ) compared with older patients. Global function at discharge remained lower in older patients than younger patients ( 91 versus $94 ; \mathrm{P}=0.002$ ). The duration of rehabilitation and length of stay were similar between the two groups.

CONCLUSION: A comprehensive inpatient pulmonary rehabilitation program is beneficial in selected patients 80 years of age or older.

Key Words: Aged; Age factors; Elderly; Lung diseases; Physical therapy; Rehabilitation

Chronic respiratory disease is common and its prevalence is Uincreasing as the life expectancy of the Canadian population is extended by improved medical care. Most of these patients have chronic obstructive pulmonary disease (COPD), which results in functional impairment related to dyspnea and associated muscle deconditioning $(1,2)$. The use of medical resources by patients with COPD is immense $(3,4)$ and will increase due to a doubling in the expected prevalence of chronic lung disease by 2015 (5).

Because many patients remain significantly impaired despite optimal medical management of their chronic respiratory disease,

\section{La réadaptation pulmonaire améliore la capacité fonctionnelle chez les patients de 80 ans ou plus}

OBJECTIFS : Selon des éléments probants limités, la réadaptation pulmonaire améliore la capacité à l'exercice chez les patients âgés atteints d'une maladie respiratoire chronique. La présente étude visait à déterminer si des patients de 80 ans ou plus bénéficieraient d'une réadaptation pulmonaire, à l'instar de patients plus jeunes.

MÉTHODOLOGIE : Les issues ont été comparées chez 230 patients hospitalisés consécutifs atteints d'une maladie pulmonaire modérée à grave qui avaient participé à un programme complet de réadaptation pulmonaire pendant une période d'un an. Les issues incluaient la distance du test de marche de 6 minutes (TM6M), le nombre de marches franchies en 2 minutes (MF2M), les échelles de dyspnée de Borg après l'effort et des indices fonctionnels objectifs.

RÉSULTATS : On ne remarquait aucune différence entre les patients âgés ( 80 à 91 ans, $n=43)$ et plus jeunes $(n=187)$ pour ce qui est du sexe, du volume expiratoire maximal par seconde (moyenne $0,77 \mathrm{~L}$ par rapport à $0,72 \mathrm{~L})$ ou du nombre de diagnostics médicaux chroniques $(2,4$ par rapport à 2,7). Les patients âgés étaient moins souvent des survivants d'une ventilation mécanique (2,3\% par rapport à $16 \%)$. Le TM6M (133 m par rapport à $144 \mathrm{~m} ; \mathrm{P}=0,48)$ et les $\mathrm{MF} 2 \mathrm{M}(5,2$ marches par rapport à 6,5 ; $\mathrm{P}=0,067$ ) étaient similaires au départ, mais la fonction globale était plus faible ( 85 par rapport à $89 ; \mathrm{P}=0,040$ ) chez les patients âgés que chez les patients plus jeunes, respectivement. Après la réadaptation pulmonaire, toutes les issues étaient considérablement plus positives, quel que soit l'âge (toutes les comparaisons avant-après, $\mathrm{P}<0,0001$ ). L'état des patients plus jeunes s'améliorait, avec de meilleurs résultats du TM6M (231 m par rapport à $185 \mathrm{~m} ; \mathrm{P}=0,004)$ et des résultats similaires de $\mathrm{MF} 2 \mathrm{M}$ $(9,3$ marches par rapport à 7,$9 ; \mathrm{P}=0,070)$ au congé, comparativement aux patients âgés. La fonction globale au congé demeurait plus faible chez les patients âgés que chez les patients plus jeunes (91 par rapport à 94; $\mathrm{P}=0,002$ ). La durée de la réadaptation et la période d'hospitalisation étaient similaires entre les deux groupes.

CONCLUSION : Un programme complet de réadaptation pulmonaire pour les patients hospitalisés est bénéfique chez des patients sélectionnés de 80 ans ou plus.

increased attention has focused on pulmonary rehabilitation as a means of improving the chronic dyspnea, limited function and quality of life of these patients (6). However, the use of this modality remains somewhat limited because it is costly and not universally available (7). Where programs do exist, the selection of appropriate patients is an important issue. Generally, as seen in published trials, enrolled subjects tend to be younger than the general population of patients with COPD $(2,8-11)$. This suggests there is an implicit bias against 'older' patients in exercisebased programs. Given that physicians will be faced with increasing numbers of elderly patients with COPD (3-5), it is

Departments of Medicine and Physiotherapy, Mount Sinai Hospital Center, Montreal, Quebec

Correspondence and reprints: Dr MA Baltzan, Mount Sinai Hospital Center, 5690 Cavendish Boulevard, Cote St-Luc, Montreal, Quebec

H4W 1S7. Telephone 514-369-2222, fax 514-369-2225, e-mail marc.baltzan@clinepi.mcgill.ca 
important to know whether age should be an important criteria in the selection process for pulmonary rehabilitation programs.

The objective of the present study was to compare the effectiveness of inpatient pulmonary rehabilitation designed to improve exercise tolerance and functional capacity in patients with chronic lung disease 80 years of age or older with younger patients. Specific outcomes assessed were the 6 min walk distance and the degree of dyspnea at the end of the test; the ability to climb up and down a standard set of stairs and the dyspnea after this test; and a global objective functional score rated by the physiotherapists. Secondary objectives included comparing comorbidity at time of entry and during rehabilitation, as well as the required duration of rehabilitation and total length of stay in older patients with younger patients.

\section{METHODS}

\section{Study design}

Data were evaluated on 230 consecutive patients who were admitted to the inpatient pulmonary rehabilitation program (IPRP) at Mount Sinai Hospital Center (MSHC) (Montreal, Quebec) between April 1, 1999, and March 31, 2000. To focus on the oldest age group, the population was analyzed comparing those 80 years of age or older ('older patients' [OP]) with all those younger ('younger patients' [YP]). The clinical characteristics of the subjects who enrolled were collected by interview and examination by the health professionals in the program. Patients who did not complete the rehabilitation program as planned because they either developed prohibitive complications or left early for other reasons were included in the analysis. The study was approved by the MSHC Ethics Committee.

\section{Measurements}

The following tests were performed systematically on all patients before and on completion of the IPRP program. Quality of life data were incomplete and are not reported.

Six-minute walk test: This standard measure of mobility was performed initially and repeated at weekly intervals, as well as on completion of the IPRP, on all patients according to published standards (12). The patients walked in a measured hallway with neutral encouragement for $6 \mathrm{~min}$. Practice walks were encouraged, yet no practice walk was performed because of the fatigue experienced by many of the patients after this sustained effort. Patients of all ages were observed to be able to walk for total times much shorter than the 6 min opportunity because of severe leg weakness and the requirement for rest. Dyspnea at the end of each trial was rated by the modified Borg visual analog scale (VAS) (13).

Two-minute stair climbing test: This measure of mobility was performed on all patients able to climb stairs. The number of stairs that were climbed and descended in 2 min was counted in a timed evaluation. A set of three steps and a fixed railing was used, with the patient performing as many up and down laps as possible in $2 \mathrm{~min}$. Rests were allowed. Neutral encouragement was given throughout the test. Stair climbing has been used as a measure of disability and impairment of cardiopulmonary function, as well as a predictor of postoperative complications (14). The minimal clinically important difference for this measure has been estimated to be two laps (approximately one-half of a flight of stairs).

Global Functional Score: Certified dedicated physiotherapists systematically evaluated all patients entering and ending the pulmonary rehabilitation program and computed the Global Functional Score (GFS). This structured objective assessment was developed between 1990 and 1994 and follows a standard flow sheet. This was developed using the World Health Organization's International Classification of Impairments, Disabilities and Handicaps (15) with an approach similar to the Functional Independence Measure in neurological patients (16). A complete assessment scores multiple mental, physical and functional domains. This included a basic evaluation of mental status and motivation (10 points), physical mobility with respect to the bed and room (20 points), independence with activities of daily living (17 points), $6 \mathrm{~min}$ walk distance ( 4 points), number of stairs climbed and descended in 2 min (4 points), graded muscle strength of extremities (12 points per side for arms; 9 points per side for legs). Function was assessed (16 points per arm; 12 points per leg). Finally, balance was assessed. If necessary, the Berg balance scale was performed seated, while standing and then with movement (12 points). The sum scores per individual divided by the maximum possible multiplied by 100 are reported, where, as a result, a score of 100 indicates normal function.

Validation of the GFS in the study population was performed. When retested after three months, a correlation coefficient $\rho=0.84$ was found within individuals. This scale correlated with patient quality of life as measured by the St George's Respiratory Questionnaire (17) ( $\rho$ with impact domain scores of 0.25 ). The GFS was lower in patients surviving mechanical ventilation and improved over time with recovery and rehabilitation. In the study patients, improvements in the 6 min walk test (6MWT) and 2 min stair climbing test (2MST) (reported separately) generally accounted for a 0.6 to 1.8 point improvement in the GFS. The minimal clinically important difference for GFS has been estimated to be 2 out of 100 (equivalent to a change in a category in at least three domains).

\section{IPRP}

The IPRP at MSHC employs a multidisciplinary team working to optimize physical ability, functional autonomy and social performance. Admission to the program is by referral from community physicians and pulmonary specialists. Age is not a factor in admissibility to the IPRP. The IPRP encompasses the components of education, physical exercise and psychosocial adjustment to severe chronic respiratory illness. The professionals on this team include physical and occupational therapists, physicians, specialized nurses, a social worker, dieticians, inhalation therapists, recreation therapists, psychologists and music therapists.

Patients are admitted for an anticipated three-week period. However, if intercurrent medical conditions exist or become apparent, the length of stay may be longer. The program includes therapies to strengthen both upper and lower extremity muscle groups (treadmill and bicycle exercise, weight training, stair climbing and hall walking). Teaching includes breathing techniques to improve voluntary breathing and to control and reduce dyspnea. Energy conservation during daily activities is emphasized. Patients receive education regarding medications and inhalation techniques. The structured time for each patient per week is at least $5 \mathrm{~h}$ training with a physiotherapist, $3 \mathrm{~h}$ with an occupational therapist and $2 \mathrm{~h}$ with a psychologist.

The exercise prescription includes supervised dyspnea-limited or fatigue-limited daily exercise training. This includes treadmill 
TABLE 1

Baseline characteristics of patients

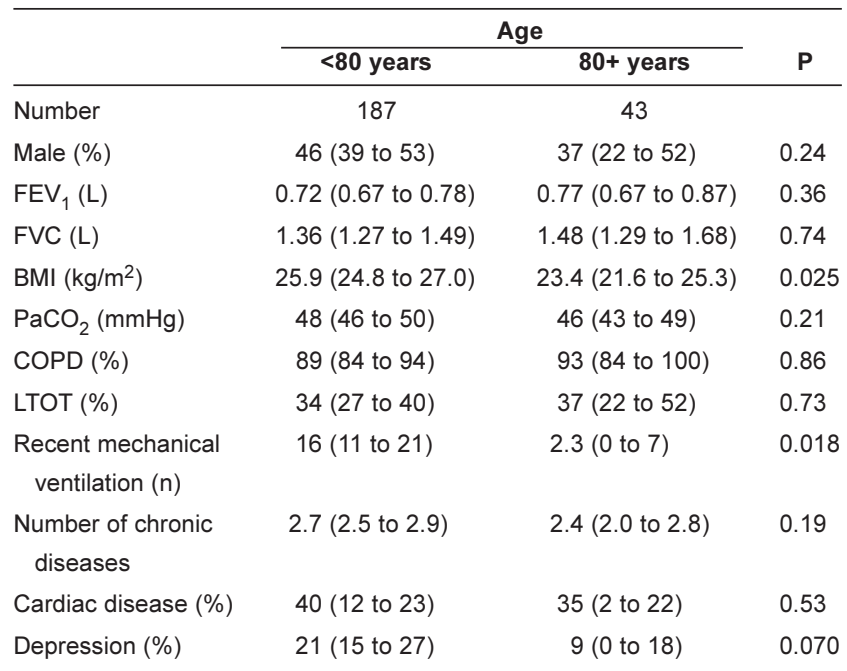

Means or percentages of each age group are presented. $95 \% \mathrm{Cl}$ are in parentheses. $P$ values are for comparisons between age group with an $F$ test for frequencies and Student's $\mathrm{t}$ test for continuous variables. BMI Body mass index; COPD Chronic obstructive pulmonary disease; FEV 1 Forced expiratory volume in $1 \mathrm{~s}$; FVC Forced vital capacity; LTOT Long-term $\mathrm{O}_{2}$ therapy; $\mathrm{PaCO}_{2}$ Partial pressure of carbon dioxide in arterial blood

walking, stationary cycling and/or free-walking. This is supervised by physiotherapists who set initial goals that substantially improve or overcome any handicaps the patients may currently face in their lives at home $(2,9,15)$. Supplemental $\mathrm{O}_{2}$ is used during training in patients with exercise-induced $\mathrm{O}_{2}$ desaturation (end-exercise oxygen saturation measured by pulse oximetry less than 90\%) and in patients who are already using home $\mathrm{O}_{2}$. The training intensity is adjusted at least weekly based on the level of dyspnea and heart rate, as well as adverse symptoms, including dizziness, fatigue and discomfort of the chest or legs. When dyspnea is determined to be the major limiting factor to effort, the exercise intensity is targeted to a Borg score of 5 or more.

\section{Statistical analysis}

Descriptive statistics (means, SDs, counts and frequencies in per cent) were used to present patients' baseline characteristics. The analysis focused on the comparisons of the changes in scores associated with rehabilitation in the two groups (OP versus YP) with an unpaired Student's $t$ tests. Analysis of the admission and discharge scores were performed in a similar manner. Confounding variables were examined between the two groups using an $\mathrm{F}$ test or with unpaired Student's $t$ test where appropriate. Multivariate analysis (18) adjusting for significant confounders (survivors of mechanical ventilation, body mass index [BMI] and depression, all with a univariate $\mathrm{P}<0.1$ ) was performed for all of the outcomes. The study population was examined for trends across age groups through inspection of histograms and any significance of a trend was tested using the $\chi^{2}$ test for trend. Per cent predicted values for forced expiratory volume in $1 \mathrm{~s}$ were calculated with respect to equations for normal values published by Crapo et al (19). Statistical significance was at the two-sided 0.05 level, and 95\% CIs were calculated.
TABLE 2

Six-minute walk distance after pulmonary rehabilitation

\begin{tabular}{lccc}
\hline & \multicolumn{2}{c}{ Age } & P \\
\cline { 2 - 3 } & $<\mathbf{8 0}$ years & $\mathbf{8 0 +}$ years & (YP vs OP) \\
\hline 6 min walk $(\mathrm{m})$ & $144(131$ to 157$)$ & $133(108$ to 158$)$ & 0.48 \\
$\quad$ Admission & $231(231$ to 244$)$ & $185(159$ to 211$)$ & 0.004 \\
$\quad$ Discharge & $<0.0001$ & $<0.0001$ & \\
$\begin{array}{l}\text { P (admission versus } \\
\text { discharge) }\end{array}$ & & & \\
Dyspnea at end of & & & \\
6 min walk (Borg scale) & & & \\
$\quad$ Admission & $4.2(3.9$ to 4.5$)$ & $3.4(2.8$ to 4.1$)$ & 0.038 \\
$\quad$ Discharge & $3.5(3.3$ to 3.8$)$ & $3.1(2.7$ to 3.4$)$ & 0.033 \\
P (admission versus & $<0.0001$ & 0.13 & \\
discharge) & & & \\
\hline
\end{tabular}

Means with $95 \% \mathrm{Cl}$ in parentheses. $P$ values are for comparisons between age groups with an unpaired Student's test, and within age groups with a paired Student's t test. OP Older patients; YP Younger patients

\section{Patient population}

\section{RESULTS}

The mean age of the 230 patients evaluated by the pulmonary rehabilitation team was $70.0 \pm 10.0$ years, of whom 102 (44\%) were men. The oldest patient was 91 years and the youngest patient was 39 years. There were 39 patients younger than 60 years, 62 patients aged 60 to 69 years, 86 patients aged 70 to 79 years and 43 patients aged 80 years of age or older (OP); of the 43 OP, 11 were aged 85 years or older. Data comparing YP with OP are presented in Table 1. BMI and mechanical ventilation within the past three months were the only variables that showed significant differences with age. The number of chronic diseases, as well as the prevalence of depression and chronic stable heart disease were not significantly different. In addition, during the rehabilitation period, a similar fraction of patients suffered acute coincident illnesses, occurring in eight of 43 $(19 \%)$ in the OP group compared with 39 of 187 (21\%) patients in the YP group $(\mathrm{P}=0.74)$. These ranged in severity from oral thrush to acute respiratory failure.

\section{MWT}

At admission, 6MWT was similar in the OP and YP groups, with very low values compared with results in other populations with COPD (Table 2). The distance walked improved significantly in both age groups after pulmonary rehabilitation (admission versus discharge $\mathrm{P}<0.001$ ). Those in the YP group improved more in absolute terms with a longer mean discharge 6MWT. However, the per cent improvement in 6MWT by the OP group was $40 \%$ (95\% CI: $-29 \%$ to $108 \%$ ) which was similar to the YP group who improved, on average, by $60 \%$ (95\% CI: $13 \%$ to $108 \%$; $=0.17$ ). Dyspnea was lower in the OP group at admission and discharge, although the absolute reduction in dyspnea with rehabilitation was similar between age groups (OP -0.4 ; 95\% CI: -1.0 to -0.2 versus YP $-0.7 ; 95 \% \mathrm{CI}:-1.0$ to -0.4 ; $\mathrm{P}=0.40$ ). Adjusted analysis found that admission 6MWT did not differ with age (OP versus $\mathrm{YP} ; \mathrm{P}=0.57)$, but was shorter on discharge for the OP group ( $\mathrm{P}=0.017)$, with similar levels of dyspnea at the end of the test for both groups. 


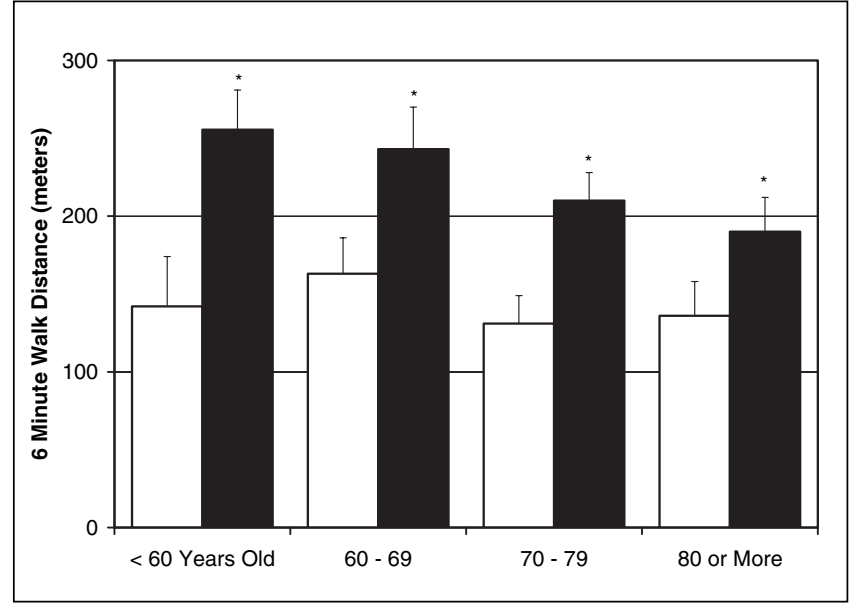

Figure 1) Changes in 6 min walk distance according to age group. Mean admission distance (open bars) and discharge distance (black bars) shown with $95 \%$ confidence upper limits. All four groups improved significantly $(\mathrm{P}<0.0001)$ from admission to discharge. $\chi^{2}$ tests for age-related trend were $P=0.16$ at admission and $P<0.001$ at discharge

\section{MST}

At admission, patients in the OP group were able to perform almost as well as those in the YP group when tested for their ability to climb and descend three-stair laps ( $\mathrm{P}=0.067$; Table 3$)$. Improvement was observed in both groups with an increased ability to climb and descend stairs at discharge $(\mathrm{P}<0.0001)$. The OP group improved after the IPRP by a mean $51 \%$ (18\% to $84 \%$ ) which was similar to the YP group who improved by a mean $41 \%$ (10\% to $73 \%$; $\mathrm{P}=0.46)$. Dyspnea after $2 \mathrm{MST}$ was, on average, lower in the OP group than in the YP group at admission and discharge $(\mathrm{P}=0.004$ at admission and $\mathrm{P}=0.014$ at discharge). Despite these differences, the reduction in dyspnea after IPRP was significant in both groups. In an adjusted analysis, no differences were found in stair climbing ability at admission, at discharge or for per cent improvement (all $\mathrm{P}>0.10$ ).

\section{GFS}

GFS was lower in the OP group than in the YP group at admission and discharge (Table 4). GFS improved significantly in both groups after pulmonary rehabilitation (both $\mathrm{P}<0.001$ ). The per cent improvement in GFS for the OP group was $7.9 \%$ (95\% CI: $4.2 \%$ to $7.9 \%$ ), similar to the improvement observed in the YP group who improved by a mean of $7.0 \%$ (95\% CI: $5.3 \%$ to $8.6 \%$; $=0.61$ ). Because GFS contains the $6 \mathrm{MWT}$ and 2MST as part of the global score, the subscores within the GFS were analyzed. Graded muscle strength and function improved, as did measures of functional physical mobility and balance. After adjusting for confounding variables, GFS remained lower in the OP group both at admission $(\mathrm{P}=0.0013)$ and discharge $(\mathrm{P}=0.009)$ with a similar per cent improvement $(\mathrm{P}=0.37)$.

\section{Duration and complications during the program}

The time spent admitted to the pulmonary physiotherapy program was similar for both age groups (Table 5). When including the total time required while admitted to hospital, including medical evaluation, as well as any interruptions of

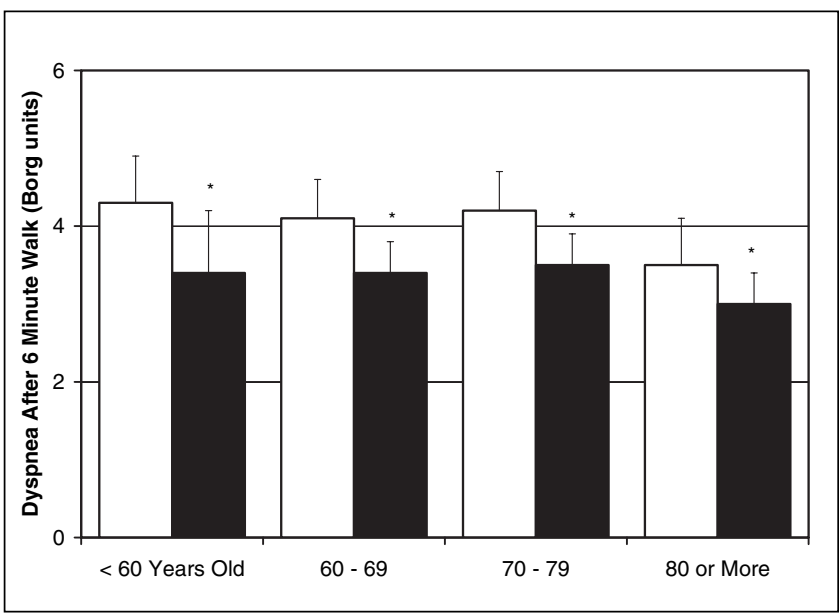

Figure 2) Changes in Borg dyspnea scores after 6 min walk according to age group. Mean admission (open bars) and discharge (black bars) dyspnea scores presented with $95 \%$ confidence upper limits. All four groups improved significantly $(P<0.0001)$ from admission to discharge. Dyspnea was significantly lower in patients 80 years of age or older at admission and discharge. $\chi^{2}$ tests for age-related trend were $P=0.22$ at admission and $\mathrm{P}=0.35$ at discharge

the rehabilitation program due to intercurrent complications, the length of stay in hospital was similar for the two groups. Adjusted analysis found that length of stay and time spent in physiotherapy remained similar in both groups. A similar fraction of patients suffered complications in all age groups, with $18.6 \%$ of the OP group and $20.9 \%$ of the YP group having had at least one complication during their hospitalization.

\section{Trends across age categories}

When the data were analyzed using four age categories, no significant trend was found for 6MWT at admission $(\mathrm{P}=0.16)$. There was a significant trend with age toward lower distance walked at discharge with older age $(\mathrm{P}<0.001)$ (Figure 1$)$. No trend was seen across age groups for per cent improvement in 6MWT. The absolute reduction in dyspnea with rehabilitation was not significantly different across age categories (Figure 2).

Stair climbing ability demonstrated no statistically significant trend across age groups at admission. After rehabilitation, there was strong trend to lower stair climbing ability with older age $(\mathrm{P}=0.002)$. Dyspnea after the 2MST demonstrated a trend to lower dyspnea with older age both at admission $(\mathrm{P}=0.043)$ and at discharge $(\mathrm{P}=0.009)$. No trend with age was seen in GFS at admission, but at discharge there was a tendency to lower functional scores in the older age categories $(\mathrm{P}=0.0025)$.

\section{DISCUSSION}

We have shown improvement in dyspnea, functional capacity with respect to walking and climbing steps, and global function in patients with chronic severe lung disease following a comprehensive pulmonary rehabilitation program. Furthermore, these improvements occurred in all measures to a similar extent regardless of age. With a similar intervention in all patients, at discharge, the OP group had lower absolute scores measured for 6MWT and global function, but similar degrees of relative improvement. The absolute improvement in the OP group is in the range of minimal clinical significance for the 6MWT (20). The likelihood of other chronic diseases 
TABLE 3

Two-minute stair test before and after pulmonary rehabilitation

\begin{tabular}{|c|c|c|c|}
\hline & \multicolumn{2}{|c|}{ Age } & \multirow{2}{*}{$\frac{P}{\text { YP vs OP }}$} \\
\hline & $<80$ years & $80+$ years & \\
\hline \multicolumn{4}{|l|}{2 min stair test (laps) } \\
\hline Admission & $6.5(5.9$ to 7.1$)$ & $5.2(4.0$ to 6.4$)$ & 0.067 \\
\hline Discharge & 9.3 (8.6 to 9.9$)$ & $7.9(6.6$ to 9.2$)$ & 0.070 \\
\hline $\mathrm{P}$ (admission versus discharge) & $<0.0001$ & $<0.0001$ & \\
\hline \multicolumn{4}{|c|}{$\begin{array}{l}\text { Dyspnea at end of } 2 \text { min stair test } \\
\text { (Borg scale) }\end{array}$} \\
\hline Admission & $4.8(4.6$ to 5.1$)$ & $3.9(3.4$ to 4.4$)$ & 0.0008 \\
\hline Discharge & 4.0 (3.7 to 4.2$)$ & $3.2(2.8$ to 3.6$)$ & 0.0016 \\
\hline $\mathrm{P}$ (admission versus discharge) & ) $<0.0001$ & $<0.0079$ & \\
\hline
\end{tabular}

Means with $95 \% \mathrm{Cls}$ in parentheses. $P$ values are for comparisons between age groups with an unpaired Student's t test, and within age groups with a paired Student's t test. OP Older patients; YP Younger patients

and coincident acute medical illnesses was similar in all age groups. The time needed for pulmonary rehabilitation, with regard to physiotherapy intervention or total length of stay, was also similar across all age groups.

The study population was, in general, severely affected in their functional capacity at admission. This is exemplified by the very low scores on the $6 \mathrm{MWT}$ at admission. This is the result of the selection of the most functionally disabled patients by referral sources, because the IPRP is unique in the area by serving severely disabled patients who would be incapable of regularly attending an outpatient program. The fact that the functional measures of walk distance in $6 \mathrm{~min}$ and stair climbing improved after the program with less dyspnea demonstrates an improved ability to do external work for the same degree of dyspnea and is evidence of a training effect of the program.

Our findings of lower discharge exercise capacity and functional ability in older patients is in keeping with previous studies of elderly subjects $(21,22)$. This has been explained physiologically by a combination of factors, including skeletal muscle atrophy (sarcopenia) with lower muscle fibre size and number (23-25). Sarcopenia is even more pronounced in patients with COPD (1). Intrinsic muscle function is also reduced in healthy older individuals, with a reduced amount of sarcoplasmic reticulum calcium release (26). Studies (23,27-29) examining the effect of endurance and strength training on healthy older subjects have shown positive effects with improvements similar to those observed in younger subjects. For example, low intensity strength training in healthy older subjects, on average, more than doubled pretraining force production (30).

The finding that global function measure at admission and discharge were significantly lower in the OP group was not surprising. General disability increases with age in epidemiological studies (31) and likely results from both the increasing prevalence and severity of chronic disease, and the behavioural and social factors that result in less regular physical activity in older age groups.

Rehabilitation programs have found great success and utility in older patients $(32,33)$. Programs tailored for rehabilitation after acute medical illness or for chronic musculoskeletal conditions have been proven to be effective in older populations
TABLE 4

Global functional score before and after pulmonary rehabilitation

\begin{tabular}{|c|c|c|c|}
\hline & \multicolumn{2}{|c|}{ Age } & \multirow{2}{*}{$\frac{P}{\text { YP vs OP }}$} \\
\hline & $<80$ years & $80+$ years & \\
\hline \multicolumn{4}{|l|}{$\begin{array}{l}\text { Global functional score } \\
(\max 100)\end{array}$} \\
\hline Admission & 89 (87 to 90$)$ & 85 (81 to 89$)$ & 0.040 \\
\hline Discharge & 94 (93 to 95 ) & 91 (88 to 93) & 0.002 \\
\hline $\begin{array}{l}\mathrm{P} \text { (admission versus } \\
\text { discharge) }\end{array}$ & $<0.0001$ & $<0.0001$ & \\
\hline
\end{tabular}

Means with 95\% Cls in parentheses. $P$ values are for comparisons between age groups with a Student's t test, and within age groups with a paired Student's t test. OP Older patients; YP Younger patients

TABLE 5

Length of program and stay in hospital

\begin{tabular}{lccc}
\hline & \multicolumn{2}{c}{ Age } & P \\
\cline { 2 - 3 } & $\mathbf{8 0}$ years & $\mathbf{8 0 +}$ years & $\mathbf{P}$ \\
\hline Days in rehabilitation & $23.1(21.9$ to 24.3$)$ & $23.1(20.3$ to 26.0$)$ & 0.98 \\
Days in hospital & $28.7(28.0$ to 31.3$)$ & $32.2(27.1$ to 37.3$)$ & 0.35 \\
\hline
\end{tabular}

Means of each measure per group are presented. 95\% Cls are in parentheses. $P$ values are for comparisons between age groups with a Student's t test

(34). Cardiac rehabilitation programs have shown physiological benefits which occurred regardless of age (35-37). Observations of small numbers of patients in other centres have found that older patients improve substantially with pulmonary rehabilitation $(38,39)$ and that age was not a significant determinant of response to exercise training compared with measures of muscle weakness (40). All of these programs shared the same general goals of improved functional status, improved quality of life and empowering the patients to be more able to meet their own needs. Our population was severely compromised at entry, which was demonstrated by the very low 6 min walk distances. Whether the age effects observed here are applicable to pulmonary rehabilitation in the outpatient setting requires further study. Subgroup analysis of smaller numbers in other centres provided evidence that age is not a factor in response to outpatient pulmonary rehabilitation (40).

King et al (41) have observed a bias against referring older patients for rehabilitation. In their review of all patients participating in a regional, publicly funded cardiac rehabilitation program, implicit selection against older patients was evident. Patients who were 70 years of age or older were $58 \%$ less likely to undergo rehabilitation regardless of important comorbid conditions.

In the present study population, the OP group showed differences compared with the YP group. On average, they had a lower BMI and were less likely to be referred after mechanical ventilation. This may reflect the selection biases in acute medical care operating in other centres, as well as the lower likelihood of older patients to receive and survive mechanical ventilation.

Exercise-induced improvements in functional capacity and mobility with an increased tolerance to dyspnea have been reported following low intensity exercise training that did not result in changes in cardiorespiratory function or peripheral 
muscle adaptations $(42,43)$. The symptom-limited training in our study also resulted in similar improvements across all age groups. We cannot generalize our results to the potential effects of cardiopulmonary exercise test-directed training in older age groups.

One limitation of our study was that the patients were selected before admission and were not representative of all patients with chronic severe respiratory disease. Our patients were selected based on their likelihood to benefit from rehabilitation. Referring physicians spanning a wide spectrum ranging from outpatient general practice to critical care send applications for admission. Applications are refused if substantial impediments to rehabilitation are suspected to exist, such as severe or unstable cardiac disease, cognitive dysfunction, untreated depression or severe musculoskeletal disease.

\section{REFERENCES}

1. Bernard S, Leblanc P, Whittom F, et al. Peripheral muscle weakness in patients with chronic obstructive pulmonary disease. Am J Respir Crit Care Med 1998;158:629-34.

2. American Thoracic Society. Pulmonary rehabilitation - 1999. Am J Respir Crit Care Med 1999;159:1666-82.

3. Lacasse Y, Brooks D, Goldstein RS, for the COPD and Rehabilitation Committee of the Canadian Thoracic Society. Trends in the epidemiology of COPD in Canada, 1980 to 1995. Chest 1999;116:306-13.

4. Cydulka RK, McFadden ER Jr, Emerman CL, Sivinski DD, Pisanelli W, Rimm AA. Patterns of hospitalization in elderly patients with asthma and chronic obstructive pulmonary disease. Am J Respir Crit Care Med 1997;156:1807-12.

5. Feenstra TL, van Genugten MLL, Hoogenveen RT, Wouters EF, Rutten-van Molken MP. The impact of aging and smoking on the future burden of chronic obstructive pulmonary disease: A model analysis in the Netherlands. Am J Respir Crit Care Med 2001;164:590-6.

6. Lacasse Y, Wong E, Guyatt GH, King D, Cook DJ, Goldstein RS, Meta-analysis of respiratory rehabilitation in chronic obstructive pulmonary disease. Lancet 1996;348:1115-9.

7. Brooks D, Lacasse Y, Goldstein RS. Pulmonary rehabilitation programs in Canada: National survey. Can Respir J 1999;6:55-63.

8. Pulmonary Rehabilitation: Joint ACCP/AACVPR evidence-based guidelines. ACCP/AACVPR Pulmonary Rehabilitation Guidelines Panel. American College of Chest Physicians. American Association of Cardiovascular and Pulmonary Rehabilitation. Chest 1997;112:1363-96.

9. Troosters T, Gosselink R, Decramer M. Short- and long-term effects of outpatient rehabilitation in patients with chronic obstructive pulmonary disease: A randomized trial. Am J Med 2000;109:207-12.

10. Griffiths TL, Burr ML, Campbell IA, et al. Results at 1 year of outpatient multidisciplinary pulmonary rehabilitation: A randomized controlled trial. Lancet 2000;355:362-8.

11. Finnerty JP, Keeping I, Bullough I, Jones J. The effectiveness of outpatient pulmonary rehabilitation in chronic lung disease: A randomized controlled trial. Chest 2001;119:1705-10.

12. Guyatt GH, Sullivan MJ, Thompson PJ, et al. The 6-minute walk: A new measure of exercise capacity in patients with chronic heart failure. CMAJ 1985;132:919-23.

13. Wilson RC, Jones PW. A comparison of the visual analogue scale and modified Borg scale for the measurement of dyspnoea during exercise. Clin Sci 1989;76:277-82.

14. Girish M, Trayner E Jr, Dammann O, Pinto-Plata V, Celli B. Symptom-limited stair climbing as a predictor of postoperative pulmonary complications after high-risk surgery. Chest 2001;120:1147-51.

15. World Health Organization. International Classification of Impairments, Disabilities, and Handicaps. Geneva: World Health Organization, 1980:1-32.

16. Brosseau L, Wolfson C. The inter-rater reliability and the construct validity of the Functional Independence Measure (FIM) for multiple sclerosis subjects. Clin Rehabil 1994;8:107-15.
Age is explicitly not a criterion for refusal once an application is received.

\section{CONCLUSIONS}

We found that older patients with chronic respiratory disease may benefit significantly from pulmonary rehabilitation. The relative improvements in 6 min walk distance, stair climbing ability and global functional capacity were similar to those in the younger patients of the study population. Therefore, we conclude that age alone should not be a contraindication to entry into a comprehensive pulmonary rehabilitation program for individuals who appear to be medically stable and capable of participating in an exercise program.

FUNDING: The study was funded by the Mount Sinai Hospital Research Center.
17. Jones PW, Quirk FH, Baveystock CM, Littlejohns P. A self-complete measure of health status for chronic airflow limitation. The St. George's Respiratory Questionnaire. Am Rev Respir Dis 1992;145:1321-7.

18. Kleinbaum DG, Kupper LL, Muller KE. Applied Regression Analysis and Other Multivariable Methods, 2nd edn. Belmont: Duxbury Press, 1988:102-43.

19. Crapo RO, Morris AH, Gardner RM. Reference spirometric values using techniques and equipment that meet ATS recommendations. Am Rev Respir Dis 1981;123:659-64.

20. Redelmeier DA, Bayoumi AM, Goldstein RS, Guyatt GH. Interpreting small differences in functional status: The Six Minute Walk test in chronic lung disease patients. Am J Respir Crit Care Med 1997;155:1278-82.

21. Rogers MA, Evans WJ. Changes in skeletal muscle with aging: Effects of exercise training. Exerc Sport Sci Rev 1993;21:65-102.

22. Troosters T, Gosselink R, Decramer M. Six minute walking distance in healthy elderly subjects. Eur Respir J 1999;14:270-4.

23. Frontera WR, Hughes VA, Fielding RA, Fiatarone MA, Evans WJ, Roubenoff R. Aging of skeletal muscle: A 12-yr longitudinal study. J Appl Physiol 2000;88:1321-6.

24. Lexell J, Taylor CC, Sjostrom M. What is the cause of ageing atrophy? Total number, size, and proportion of different fiber types studied in whole vastus lateralis muscle from 15- to 83-year old men. J Neurol Sci 1988;84:275-94.

25. Kent-Braun JA, Ng AV, Young K. Skeletal muscle contractile and noncontractile components in young and older women and men. J Appl Physiol 2000;88:662-8.

26. Delbono O, Renganathan M, Messi ML. Excitation-Ca2+ releasecontraction coupling in single aged human skeletal muscle fiber. Muscle Nerve Suppl 1997;5:S88-92.

27. Kraemer WJ, Fleck SJ, Evans WJ. Strength and power training: Physiological mechanisms of adaptation. Exerc Sport Sci Rev 1996;24:363-97.

28. Hurley BF, Hagberg JM. Optimizing health in older persons: Aerobic or strength training? Exerc Sport Sci Rev 1998;26:61-89.

29. Cartee GD. Aging skeletal muscle: Response to exercise. Exerc Sport Sci Rev 1994;22:91-120.

30. Harridge SD, Kryger A, Stensgaard A. Knee extensor strength, activation, and size in very elderly people following strength training. Muscle Nerve 1999;22:831-9.

31. Pinsky JL, Jette AM, Branch LG, Kannel WB, Feinleib M. The Framingham Disability Study: Relationship of various coronary heart disease manifestations to disability in older persons living in the community. Am J Public Health 1990;80:1363-7.

32. Hauer K, Rost B, Rutschle K, et al. Exercise training for rehabilitation and secondary prevention of falls in geriatric patients with a history of injurious falls. J Am Geriatr Soc 2001;49:10-20.

33. Patrick L, Leber M, Scrim C, Gendron I, Eisener-Parsche P. A standardized assessment and intervention protocol for managing risk for falls on a geriatric rehabilitation unit. J Gerontol Nurs 1999;25:40-7. 
34. Sullivan DH, Wall PT, Bariola JR, Bopp MM, Frost YM. Progressive resistance muscle strength training of hospitalized frail elderly. Am J Phys Med Rehabil. 2001;80:503-9.

35. Wenger NK, Froelicher E, Smith LK, et al. Cardiac Rehabilitation. Clinical Practice Guideline 17. (AHCPR Publication no. 96-0672). Rockville: US Department of Health and Human Services, Public Health Service, Agency for Health Care Policy and Research, and the National Heart, Lung and Blood Institute, 1995:1-32.

36. Aggarwal A, Ades PA. Exercise rehabilitation of older patients with cardiovascular disease. Cardiol Clin 2001;19:525-36.

37. Ades PA, Grunvald MH. Cardiopulmonary exercise testing before and after conditioning in older coronary patients. Am Heart J 1990;120:585-9.

38. Couser JI Jr, Guthmann R, Hamadeh MA, Kane CS. Pulmonary rehabilitation improves exercise capacity in older elderly patients with COPD. Chest 1995;107:730-4.
39. Roomi J, Johnson MM, Waters K, Yohannes A, Helm A, Connolly MJ. Respiratory rehabilitation, exercise capacity and quality of life in chronic airways disease in old age. Age Ageing $1996 ; 25: 12-6$

40. Troosters T, Gosselink R, Decramer M. Exercise training in COPD: How to distinguish responders from nonresponders. J Cardiopulm Rehabil 2001;21:10-7.

41. King KM, Humen DP, Teo KK. Cardiac rehabilitation: The forgotten intervention. Can J Cardiol 1999;15:979-85.

42. Clark C J, Cochrane L, Mackay E. Low intensity peripheral muscle conditioning improves exercise tolerance and breathlessness in COPD. Eur Respir J 1996;9:2590-6.

43. Vogiatzis I, Williamson AF, Miles J, Taylor IK. Physiological response to moderate exercise workloads in a pulmonary rehabilitation program in patients with varying degrees of airflow obstruction. Chest 1999;116:1200-7. 


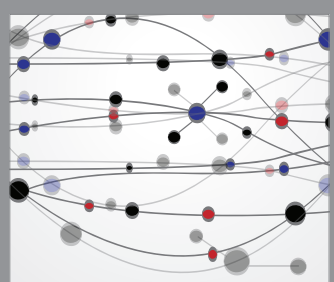

The Scientific World Journal
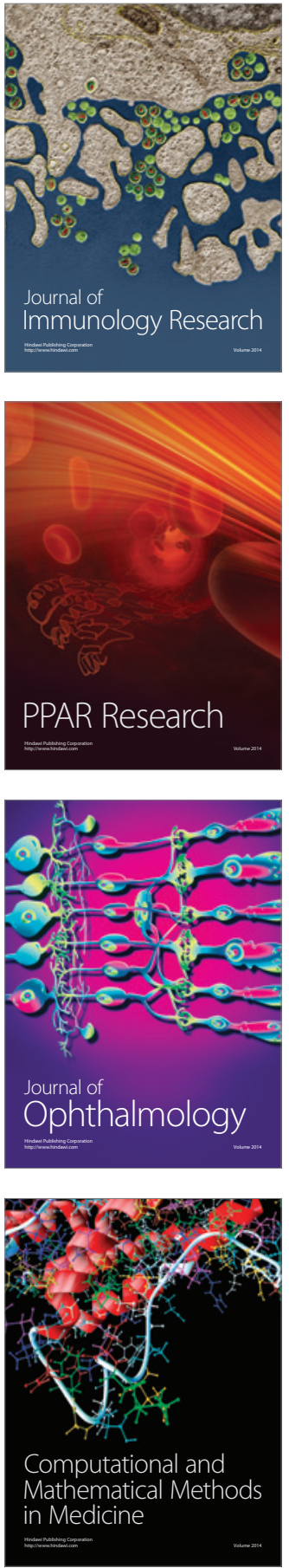

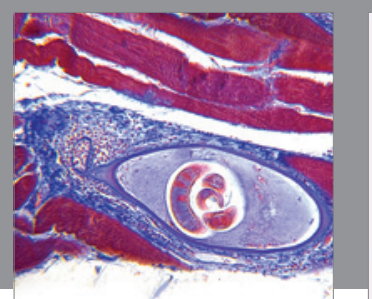

Gastroenterology Research and Practice

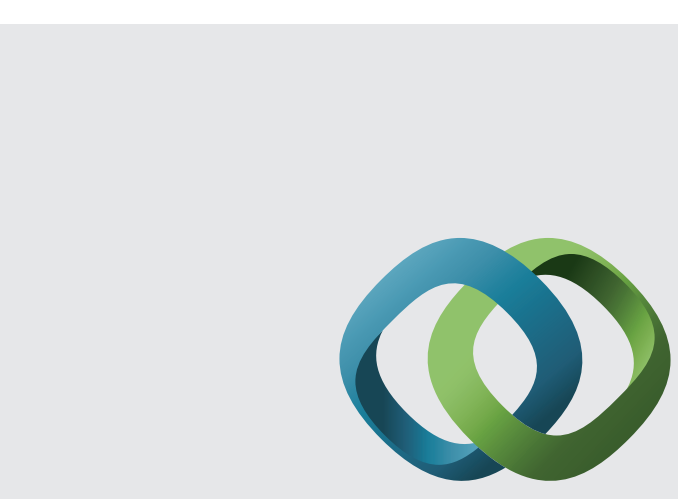

\section{Hindawi}

Submit your manuscripts at

http://www.hindawi.com
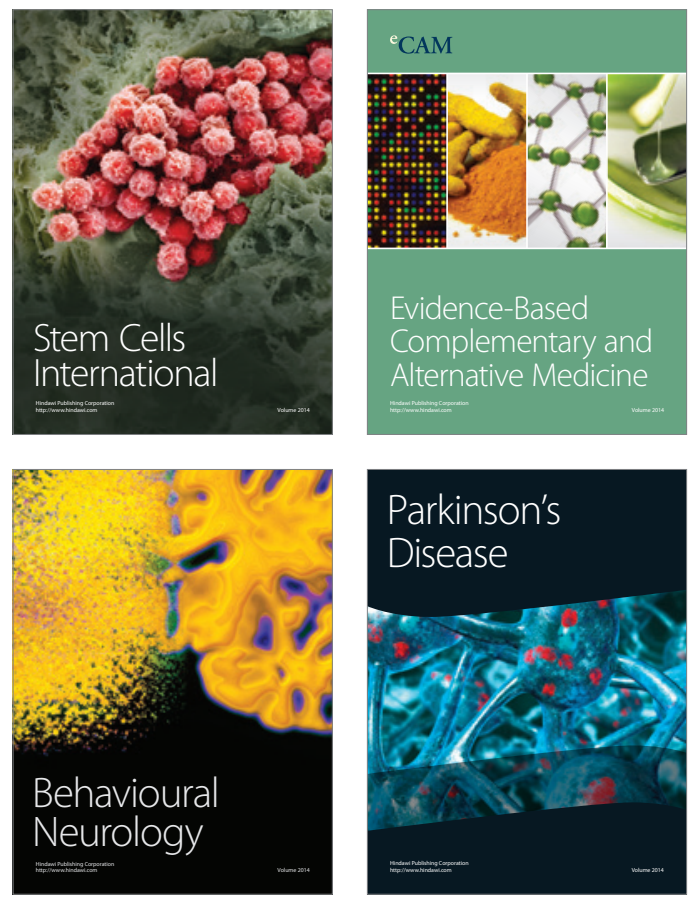
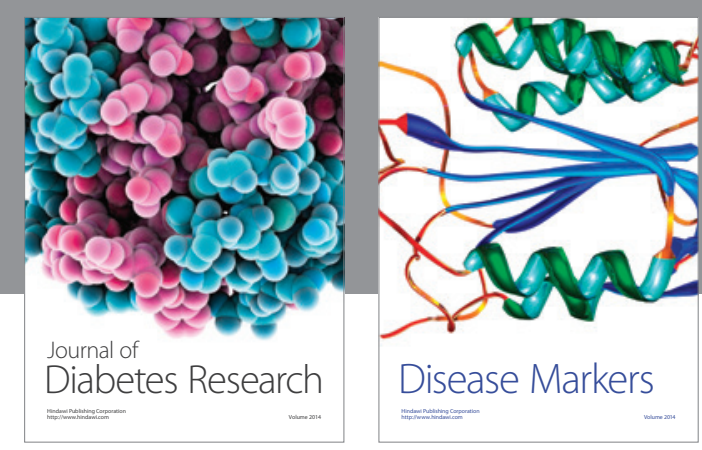

Disease Markers
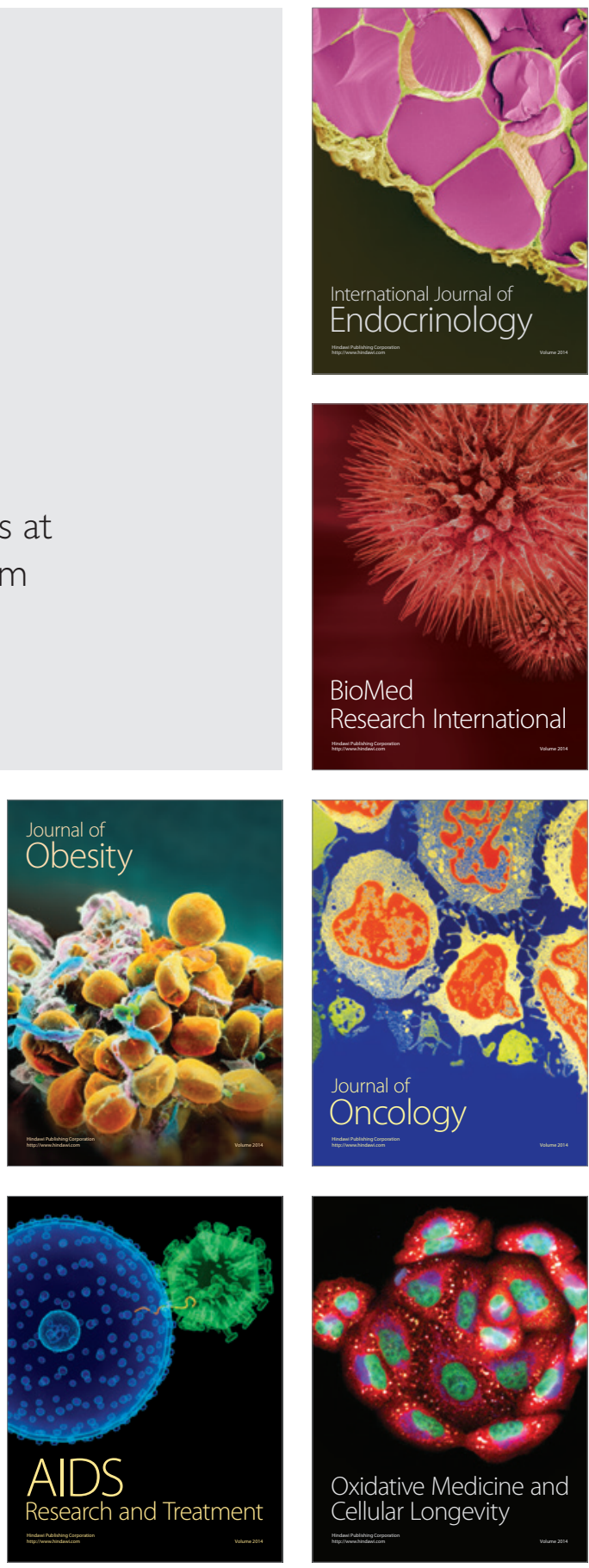